\title{
Discussion of Carrying Out Comprehensive Training of Combat Mode in Noncommissioned Institutions
}

\author{
Zhongmin Liu, Zelong Zhou, Rongyue Xie, Xianglin Tan \\ Wuhan Mechanical Technology College, Wuhan, 430075, China
}

\begin{abstract}
Comprehensive training is important to test the practicality teaching graduate students of military academies comprehensive ability and quality, is a key step to serve the students professional skills capacity for transformation, is to implement President $\mathrm{Xi}$ "able to fight, to win the war" important instructions regarding the hospital and headquarters school training closer to the troops of the implementation aspects of important decisions. Teaching institutions can carry out comprehensive drills with military training standards, improve the level of actual college education, this article will focus on the practical meaning of the characteristics of the integrated drill sergeant institutions, the necessity of comprehensive training in combat sergeant colleges and its feasibility, the last of the actual conduct of the principles to be followed by comprehensive training and attention problems were discussed.
\end{abstract}

Key words: Training, NCO, Combat, Drill

\section{INTRODUCTION}

Combat training means "under similar circumstances and conditions of combat training", is a comprehensive implementation of the "war training consistent" training principles, height close to the actual level of training through the creation of environmental conditions, strict compliance with the training requirements in line with the experiment content and training standards, flexible use of "close combat, like combat, simulated combat, in line with the actual" training various ways to minimize the gap between training and fighting between troops carry out in the future to improve the combat capability of combat missions the fundamental purpose of military practice. $[1,2]$

\section{ACTUAL CONTENT OF THE COMPREHENSIVE TRAINING AND CHARACTERISTICS}

Actual combat training exercises makes teaching more practical. Comprehensive training noncommissioned personnel training process is an important practical teaching with professional practice, skills enhancement training, professional training and other practical courses of training as important as teaching. In some military academies, comprehensive training personnel training process to become "weak", the teaching process is the weak link, the main reason for the extent of the actual importance of the integrated exercise enough, do not fully understand the comprehensive training as personnel training process of "gatekeeper" role, not straighten out "speech to war", "training for the war" relationship, leading to comprehensive training to become a routine graduation equipment pull performance, content and form set unscientific, And the subjects set out combat drills environment, from the job demand in the short term to enhance cognitive abilities slow job often leads to noncommissioned officers training students lack the ability to adapt to the battlefield. The actual combat training exercises can effectively strengthen the practice effect. Comprehensive drill sergeant institutions positioning themselves for the teaching of exercises to combat training requirements will be introduced to the multi-resource training exercise, participants will develop the noncommissioned officers "embedded" into the fighting forces, "rooted" in the combat environment, effectively achieve "two close" requirements. Combat exercises with the faculty of the institutions, grassroots army commanders and non-commissioned officers, military factories and research institutes, technical staff and students to participate in drills mixed grouping of non-commissioned officers, to carry out the process in a drill to drill field position for the classroom, to carry out the actual teaching training, truly "edge play learn", "play side edge research", "edge play while teaching", "learning to play side test" teaching effectiveness, enhance the authenticity of the teaching targeted and comprehensive training simulation battlefield environment, combat training levels have increased dramatically. [3]

Actual combat training exercises so that teaching evaluation system more rational. Comprehensive trainingas an important form of military colleges of education andtraining, aimed at a comprehensive job training graduatesworking in the real context of capacity, while the annualeducation and training programs as an important part ofcomprehensive evaluation of teaching effectiveness, ability to adapt to detect student jobs The importance of self-evident. In real combat training exercises, in addition to a comprehensive assessment of the overall exercise directed by the Ministry to exercise responsible for the implementation, assessment of students participating non-commissioned officers will be participating units based on certain specific weights together to evaluate and enhance the evaluation of 
rationality. The entire drill sergeant course participants will be singing "hero", will follow combat training requirements assume corresponding responsibilities, its role teachers play, base security personnel, factory technicians, grassroots army commander and other institutions can not be separated protection and guidance of the parties, and the parties participating students as a comprehensive capacity assessment team members, mentors and evaluators play a dual role, highlighting the dominant position of students in the actual combat training exercises. As the nature of the exercise test assessment, comprehensive training in actual combat training courses conducted evaluation criteria that is "closer to the standard two." According to the specific requirements of the headquarters on education and training institutions closer to the troops in combat of comprehensive training session, whether it is exercise or subject to set the scene dispatch areas, the development of future wars must be close to the model, and strive to enhance the combat capability of the students sergeant. In the course of the exercise, expertise and training capacity assessment is a core group, closely linked to personnel training programs, increase the intensity of the Joint Steering evaluation, educational resources play parties, the "whole process, all the elements, the whole object" of the assessment.

\section{THE NEED TO CARRY OUT DRILLS ACTUAL COMBAT}

NCO students are the main force combat effectiveness and continuity is the main force of the future battlefield equipment maintenance and support forces, army soldiers are the backbone of the team, can play a reasonable role in the non-commissioned officers on the battlefield, the war largely determines victory or not, but compared to actual combat drill sergeant trainees develop a comprehensive adaptation and battle battlefield disposal capacity provided training platform. That noncommissioned personnel training objectives is to develop four capabilities: professional skills, group training, management skills and ability to do the forces of ideological and political work, and make full use of the integrated combat drills this platform, students play the initiative, walkthrough guide students to actively organize and participate in drills subjects to formulate, implement, review, earnestly implement the "teacher-led, student body," the education requirements, standards of training and orientation to the height of the war. [4]

Comprehensive training to actual combat, "able to fight, to win the war" strong military targets as a guide to preparations for military struggle and educational institutions closer military training, close combat for traction, high information literacy noncommissioned officers to train personnel for the purpose, and actively adapt based information system the combat equipment support requirements, conduct training and assessment, highlighting the students "practice" as the main body, simulated combat environment, organizations turn into the level of combat readiness, motor assembly in accordance with the army carries out basic formations under conditions of informatization and equipment support combat mission mode evacuation configuration, combat training, combat implementation battlefield repairs, dismantling and summarize other aspects of real soldiers with real equipment exercise. By actual combat drills, to further enhance student readiness awareness, strengthen professional theoretical knowledge and practical skills combine quality and style of thinking will exercise, training standards and narrowing the gap between the requirements of the battlefield.

\section{CARRY OUT THE FEASIBILITY OF THE INTEGRATED COMBAT DRILLS}

In real combat training exercises set of educational resources in multi-battle, make full use of the advantages of education resources noncommissioned officer academies, while coordinating grassroots forces and tactical training base of high quality drill sites and research institutes, factories comprehensive technical support resources, plan military advantage of education training resources, a comprehensive evaluation of the practical teaching and graduate together, to really "practice of war, war speech" of resources in personnel training process optimization configuration, and ultimately achieve "resources to co-ordinate the overall security" effect, enhance the level of combat training.

Comprehensive drill sergeant colleges teaching tactical drills as necessary to establish joint operations directorate, command headquarters and other types of exercise, highlighting the combat characteristics. The whole exercise carried out by the independent student organization, the noncommissioned colleges, training bases, joint director of the Ministry of grassroots units and research institutes and factories composed of drills conducted dispatch. To achieve command and control, intelligence, integration and technology sharing between units must be performed by the participating party coalition exercises command authority, we must play to their strengths, but also to emphasize the close cooperation between them, directing department and agencies at all levels of command to abandon the professional mindset bondage, historical inertia mechanized warfare concept, consider the issue from the overall combat effectiveness, through the "student speech, teachers point" training mode, so drills and combat seamlessly, becoming practical classroom teaching.

\section{CONDUCT REAL COMBAT TRAINING EXERCISES SHOULD FOLLOW THE PRINCIPLES AND ATTENTION PROBLEMS}

Since the units participating in the daily military operations did not formulate corresponding linkage mechanism, education and training resources are relatively dispersed. The launch of the integrated combat training 
exercise was mobilizing resources provide an opportunity to become an associate of education personnel participating parties ties. In the course of the implementation of the exercise, equipment, technical support forces, space, supplies, communications bands such as the use of scheduling must be unified management, reasonable configuration. Through education and training to achieve the optimal allocation of resources, enhance the overall combat effectiveness of comprehensive training.

Now an important part of a comprehensive drill sergeant as personnel training colleges into vocational and technical education level noncommissioned personnel training program participants. How to improve the overall relevance and effectiveness of exercise is the current problems to be solved. To enhance the level of actual combat drills must be coordinated by a multi-unit, relying solely on the power of the institutions will make drill sergeant effect is limited, we must establish a scientific and rational exercise system, regulate the functions and responsibilities of the relevant units. Headquarters does not give specific tasks to participating units of personnel training, and exercises for the implementation of the integrated combat specific tasks, establish long-term communication mechanism and evaluation system is currently a serious problem, can not "go it alone" must be made by headquarters led the development of appropriate regulations, to "work together" effect, the formation of an institutional guarantee for the smooth implementation of the exercise to clear institutional barriers.

"How to fight the battle, soldiers on how to practice," consistent training warfare, consistent coaching, has always been the eternal principles of military training. From the "true", "difficult", "solid" start serious training outstanding training, command training and technical support to strengthen training courses normative, co- ordinate planning and implementation of related subjects. From the reality of war, combined with non-commissioned officers and Deepen Comprehensive Security Research tactical command and equipment, scientific and reasonable exercise job functions, refine organizational processes, the drill operability and targeted students closer to the level of non-commissioned officers, and thus enhance the exercise guidance enable students to enter as soon as possible the role of non-commissioned officers, into the battlefield environment, highlighting the actual characteristics of exercise

\section{CONCLUSION}

This paper presents comprehensive training of combat mode in noncommissioned institutions. Through the tactics given in the teaching practice, the NCO students in NCO academy will obtain the ability in real battlefield.

\section{INTRODUCTION OF AUTHORS}

* Corresponding author. E-mail:1137645276@qq.com

This project is supported by Teaching Reform Funding of Wuhan Mechanical Technology College.

\section{REFERENCES}

[1 ] Ma Kaesong, Li Yanzhe. Army exercises and evaluation system. PLA Publishing House, 2007, pp. 1-8.

[2] Li Fusheng. Equipment support training exercises. PLA Publishing House, 2003, 13 (3): 173-183.

[3] Heads of agencies exercise organization and implementation. PLA Publishing House, 2004, pp. 57-58.

[4] Wu Ying, Yangsan Min. Drill-based information system integrated teaching reform, continuing education, 2013, pp. 122-123. 